Published in final edited form as:

Org Lett. 2018 April 06; 20(7): 1898-1901. doi:10.1021/acs.orglett.8b00439.

\title{
Synthesis and Stereochemical Assignment of Arenolide
}

\author{
Xun Liu, Chunrui Sun, Scott Mlynarski, and James P. Morken \\ Department of Chemistry, Merkert Chemistry Center, Boston College, Chestnut Hill, \\ Massachusetts 02467, United States
}

\section{Abstract}

The convergent synthesis of candidate stereoisomers of the natural product arenolide was accomplished using recently developed catalytic boron-based reactions. Comparison of the spectral data for candidate structures with that reported for the authentic natural product revealed the likely stereostructure of the natural compound.

\section{Graphical Abstract}

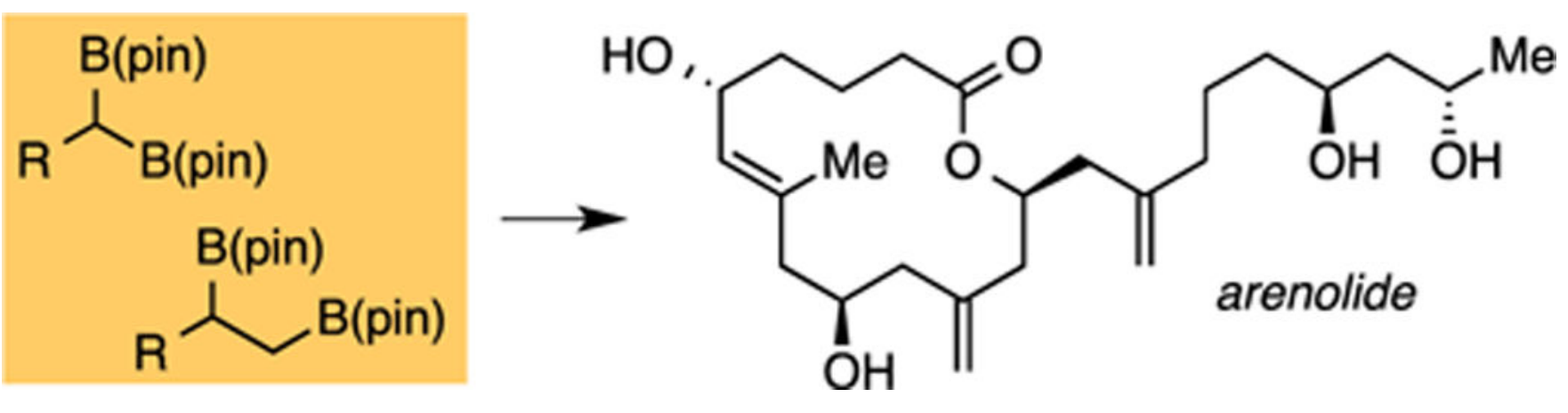

The natural product arenolide (Scheme 1a), together with three other diterpenes, were isolated from a specimen of Dysidea sp. by Lu and Faulkner in 1998. ${ }^{1}$ While arenolide demonstrated only modest cytotoxicity against $\mathrm{HCT}$ human colon carcinoma cells $\left(\mathrm{IC}_{50}: 21\right.$ $\mathrm{mM})$ and $\mathrm{A} 2780$ human ovarian carcinoma cells $\left(\mathrm{IC}_{50}: 9.8 \mathrm{mM}\right)$, it was noted that much of the compound may have decomposed prior to the assay, leaving its true biological activity in question. Of further interest, it was noted that macrolides had yet to be isolated from the Dysidea species, suggesting that arenolide may have been secreted by another producing organism and then absorbed by the sponge. In terms of structure, the macrocyclic core of arenolide is reported to be a fourteen-membered ring bearing an attached hydroxylated sidechain. While the relative configuration of the macrocycle was assigned by NOESY analysis, the relative configuration at $\mathrm{C} 19$ and $\mathrm{C} 21$ was left unassigned. Moreover, the absolute configuration of arenolide was not established. For these reasons, and to study the

*Corresponding Author : morken@bc.edu.

ASSOCIATED CONTENT

Supporting Information

The Supporting Information is available free of charge on the ACS Publications website.

Supporting Information Placeholder 
utility of recently-developed borylation methods under development in our laboratory, we undertook the synthesis of candidate stereoisomers of arenolide with the goal of establishing its overall stereostructure.

To streamline our efforts toward arenolide, we examined the spectral data reported for the natural product. Importantly, Lu and Faulkner employed COSY, HMQC and HMBC to completely assign the ${ }^{1} \mathrm{H}$ and ${ }^{13} \mathrm{C}$ NMR spectra and provided the observation that the ${ }^{13} \mathrm{C}$ resonances for C-19 and C-21 reside at $\delta 69.1$ and $65.5 \mathrm{ppm}$. Employing a correlation first established by Hoffmann ${ }^{2}$ and recently employed by Bruckner ${ }^{3}$, the chemical shifts reported for the $\mathrm{C}-19$ and $\mathrm{C}-21{ }^{13} \mathrm{C}$ resonances are strongly supportive of a 1,3-anti relative configuration (see Supporting Information (SI) for details) and thus, compounds $\mathbf{1}$ and $\mathbf{2}$, were targeted for synthesis.

Recently, a number of stereochemically-complex, densely functionalized natural products have been prepared using chiral organoboron based synthesis methods. ${ }^{4}$ Along these lines, our group has developed convergent catalytic methods to efficiently construct chiral organoboronic esters (Scheme 1b), and we envisioned these might facilitate the construction of arenolide. Critical synthetic connections for arenolide assembly are illustrated in Scheme 1c. We considered that the macrolactone would be closed by intramolecular esterification, and an advanced intermediate might be derived from alkene diboration/cross-coupling sequences ${ }^{5}$ involving an alkene at $\mathrm{C} 9 / \mathrm{C} 10$ of $\mathbf{3}$ and alkenyl chloride $\mathbf{4}$; a second diboration/ cross-coupling sequence involving an alkene at C13/C14 and alkenyl chloride 5 would complete the carbon skelton. Importantly, we anticipated ready access to substrate $\mathbf{3}$ through asymmetric cross-coupling of a 1,1-geminal bis(boronic) ester to establish the carbinol at C5 in compound $\mathbf{3}^{6}$

Synthesis of fragment $\mathbf{3}$ commenced with readily available bis(boryl) methane ${ }^{7}$, which was deprotonated by treatment with lithium tetramethylpiperidide (LiTMP) and then used in an $\mathrm{S}_{\mathrm{N}} 2$ alkylation of TBS-protected 4-bromo-1-butanol (Scheme 2). ${ }^{8}$ The product 1,1bis(boronate) 6 was then subjected to an enantioselective cross coupling with vinyl bromide $\mathbf{7}$ in the presence of $1 \mathrm{~mol} \% \mathbf{L 1} \cdot \mathrm{PdCl}_{2}{ }^{6 \mathrm{~b}}$ as catalyst to afford secondary boronate $\mathbf{8}$ in modest yield (predominant byproduct is protodeboronation) and good enantioselectivity; oxidation and TBS protection furnished $\mathbf{9}$. The monosubstituted alkene in $\mathbf{9}$ was an excellent substrate for catalyst-controlled stereoselective diboration and, in the presence of $\operatorname{Pt}(\mathrm{dba})_{3} /$ $(R, R)-\mathbf{L} 2^{9}$, this reaction furnished 1,2-bis(boronate) $\mathbf{1 0}$ in good yield and stereoselectivity. The vicinal bis(boronate) 10 engaged in efficient $\mathrm{Pd} / \mathrm{RuPhos}{ }^{10}$-catalyzed cross-coupling with readily available alkenyl bromide $\mathbf{1 1}$ (see SI) and, after oxidation ${ }^{11}$ and TBSprotection, delivered 12. Finally, a second Pt-catalyzed enantioselective diboration, this time with $(S, S)$-L2 2 as ligand, furnished cross-coupling substrate $\mathbf{1 3}$ in excellent yield and stereocontrol.

With fragment $\mathbf{1 3}$ in hand, the synthesis of the side-chain was then pursued (Scheme 3). Readily available $(S)$-propylene oxide was treated with vinyl magnesium bromide and the product protected as a silyl ether giving $\mathbf{1 5} .{ }^{12}$ While Pt-catalyzed asymmetric diboration is more efficient and slightly more selective than our first-generation carbohydrate-catalyzed diboration ${ }^{13}$ employing TBS-DHG as catalyst, the later process is less expensive to operate 
on larger scale and was selected for preparation of $\mathbf{1 6}$. Following carbohydrate-catalyzed diboration, Pd/RuPhos-catalyzed cross-coupling and oxidation furnished $\mathbf{1 6}$ in modest yield, but high stereoselectivity. Subsequent protection to give $\mathbf{1 7}$, followed by sequential 9-BBN hydroboration and B-alkyl Suzuki coupling ${ }^{14}$ with 1,1-dichloroethylene, proceeded in outstanding yield to furnish cross-coupling partner 18.

Suzuki-Miyaura cross-coupling of $\mathbf{1 3}$ and $\mathbf{1 8}$ with $\mathrm{Pd} / \mathrm{RuPhos}$ furnished 19 in moderate yield (60\%, Scheme 4). Selective desilylation of compound 19 delivered primary alcohol $\mathbf{2 0}$, which was then subjected to Dess-Martin periodinane ${ }^{15}$ oxidation, followed by Pinnick oxidation ${ }^{16}$ to furnish carboxylic acid 21. Importantly, the remaining boronic ester in compound 21 did not appear to be perturbed during this oxidation sequence and, having served its role as a masked hydroxyl group over several steps of synthesis, was then oxidized; the obtained alcohol was subjected to Yamaguchi lactonization ${ }^{17}$ to afford a fourteen-membered lactone 22. Finally, after global deprotection, compound $\mathbf{1}$ was isolated.

Using a similar synthesis strategy, stereoisomer 2 was also prepared (see SI for details). Spectral data for both stereoisomers was collected and compared. While comparison of ${ }^{1} \mathrm{H}$ NMR was not helpful for establishing stereoisomer identity, examination of ${ }^{13} \mathrm{C}$ of NMR spectra was informative. Comparing ${ }^{13} \mathrm{C}$ NMR spectra revealed significant differences between stereoisomer $\mathbf{2}$ and the natural product (root mean square $(\mathrm{rms})$ deviation $=0.10$ $\mathrm{ppm}$ ) whereas ${ }^{13} \mathrm{C}$ NMR spectra for stereoisomer $\mathbf{1}$ showed much closer alignment with spectral data reported for arenolide ( $\mathrm{rms}$ difference $=0.04 \mathrm{ppm}$ ). Of note, two resonances for isomer 2 (C16 and C19) exhibited ca. 0.3 ppm difference from the reported values for arenolide (Scheme 5). Similarly, the exocyclic methide (C25) for compound 2 exhibited a $0.14 \mathrm{ppm}$ difference from the natural product. In terms of absolute configuration, the optical rotation measured for compound $\mathbf{1}$ is $[\mathrm{a}]_{\mathrm{D}}+6.00^{\circ}\left(c 0.067, \mathrm{CHCl}_{3}\right)$, while the value reported for arenolide is $[\mathrm{a}]_{\mathrm{D}}+13.0^{\circ}(c 0.64, \mathrm{CHCl} 3)$. Collectively, the evidence suggests that the structure of arenolide is that depicted for compound $\mathbf{1}$.

In summary, we have completed the total synthesis of stereoisomers of the natural product arenolide employing boron-based asymmetric transformations in place of more common carbonyl-based C-C bond constructions. Comparison of physical data suggests that compound $\mathbf{1}$ is most likely the structure of naturally occurring arenolide.

\section{Supplementary Material}

Refer to Web version on PubMed Central for supplementary material.

\section{ACKNOWLEDGMENT}

This work was supported by the NIH (NIGMS 59417).

\section{REFERENCES}

(1). Lu Q; Faulkner DJ J. Nat. Prod. 1998, 61, 1096. [PubMed: 9748373]

(2). Hoffmann RW; Weidmann U Chem. Ber. 1985, 118, 3980.

(3). Diehl J; Brü R Eur. J. Org. Chem. 2017, 278. 
(4). For recent total syntheses that employ organoboron intermediates, see: (a) Wu J; Lorenzo P; Zhong S; Ali M; Butts CP; Myers EL; Aggarwal VK Nature 2017, 547, 436. [PubMed: 28748934] (b) Bootwicha T; Feilner JM; Myers EL; Aggarwal VK Nature Chem. 2017, 9, 896. [PubMed: 28837173] (c) Li J; Ballmer SG; Gillis EP; Fujii S; Schmidt MJ; Palazzolo AME; Lehmann JW; Morehouse GF; Burke MD Science 2015, 347, 1221. [PubMed: 25766227] (d) Woerly EM; Roy J; Burke MD Nature Chem. 2014, 6, 484. [PubMed: 24848233] (e) Feng F; McGrath KP; Hoveyda AH Nature 2014, 513, 367. [PubMed: 25230659] (f) Chen L-A; Ashley MA; Leighton JL J. Am. Chem. Soc. 2017, 139, 4568. [PubMed: 28266852]

(5). Mlynarski SN; Schuster CH; Morken JP Nature 2014, 505, 386. [PubMed: 24352229]

(6). (a) Sun C; Potter B; Morken JP J. Am. Chem. Soc. 2014, 136, 6534. [PubMed: 24564423] (b) Potter B; Szymaniak AA; Edelstein EK; Morken JP J. Am. Chem. Soc. 2014, 136, 17918. See also [PubMed: 25482206] (c) Lee JCH; McDonald R; Hall DG Nature Chem. 2011, 3, 894. [PubMed: 22024887] (d) Endo K; Ohkubo T; Hirokami M; Shibata TJ Am. Chem. Soc. 2010, 132, 11033.

(7). Commercially available, see: Aldrich 794287. For synthesis, see: Hong K; Liu X; Morken JP J. Am. Chem. Soc. 2014, 136, 10581. [PubMed: 25019925]

(8). For the alkylation of 6, see: (a) Matteson DS; Moody RJ Organometallics, 1982, 1, 20.(b) Yang CT; Zhang Z-Q; Tajuddin H; Wu C-C; Liang J; Liu J-H; Fu Y; Czyzewska M; Steel PG; Marder TB; Liu L Angew. Chem. Int. Ed. 2012, 51, 528.

(9). For the utility of this catalyst in diboration, see: (a) Coombs JR; Haeffner F; Kliman LT; Morken JP J. Am. Chem. Soc. 2013, 135, 11222. [PubMed: 23862690] (b) Kliman LT; Mlynarski SN; Morken JP J. Am. Chem. Soc. 2010, 132, 13949.

(10). Milne JE; Buchwald SL J. Am. Chem. Soc. 2004, 126, 13028. [PubMed: 15469301]

(11). In our experience, the efficiency of oxidation with $\mathrm{NaOH} / \mathrm{H}_{2} \mathrm{O}_{2}$ and sodium perborate are comparable. When compounds are anticipated to be base-sensitive, we opt for the later method.22

(12). For the synthesis of 15, see: (a) Kumar P; Gupta P; Naidu SV Chem. Eur. J. 2006, 12, 1397. [PubMed: 16308881] (b) Figueroa R; Hsung RP; Guevarra CG Org. Lett. 2007, 9, 4857. [PubMed: 17949099]

(13). Fang L; Yan L; Haeffner F; Morken JP J. Am. Chem. Soc. 2016, 138, 2508. [PubMed: 26854364]

(14). (a) Liron F; Fosse C; Pernolet A; Roulland E J. Org. Chem. 2007, 72, 2220. For a review, see: [PubMed: 17311458] (b) Chemler SR; Trauner D; Danishefsky SJ Angew. Chem., Int. Ed. 2001, 40, 4544.

(15). (a) Dess DB; Martin JC J. Org. Chem. 1983, 48, 4155.(b) Dess DB; Martin JC J. Am. Chem. Soc. 1991, 113, 7277.

(16). (a) Lindgren BO; Hilsson T Acta Chem. Scand. 1973, 27, 888.(b) Kraus GA; Taschner MJ J. Org. Chem. 1980, 45, 1175.(c) Kraus GA; Roth BJ Org. Chem. 1980, 45, 4825.(d) Bal BS; Childers WE, Jr.; Pinnick HW Tetrahedron 1981, 37, 2091.

(17). Inanaga J; Hirata K; Saeki H; Katsuki T; Yamaguchi M Bull. Chem. Soc. Jpn. 1979, 52, 1989. 
a:

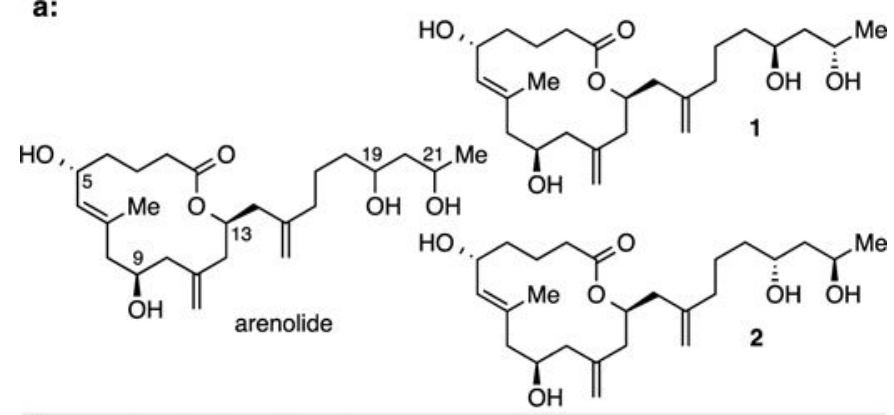

b: enantioselective diboration/cross-coupling:
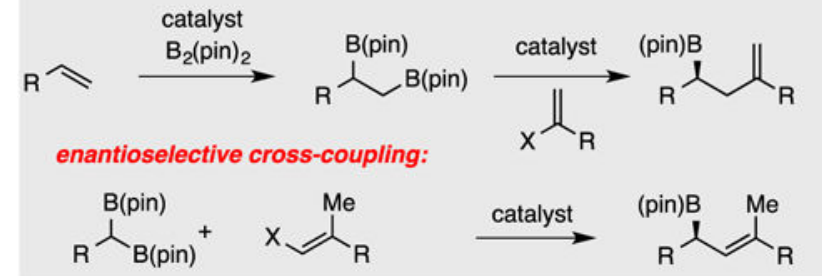

c: building blocks for construction of arenolide:

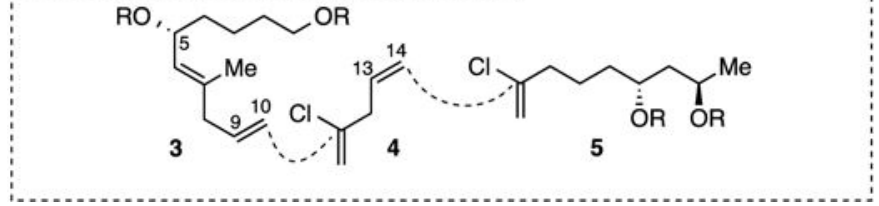

Scheme 1.

Structure of Arenolide Candidates and a Plan for Constructing them Using Boron-Based Reactions. 


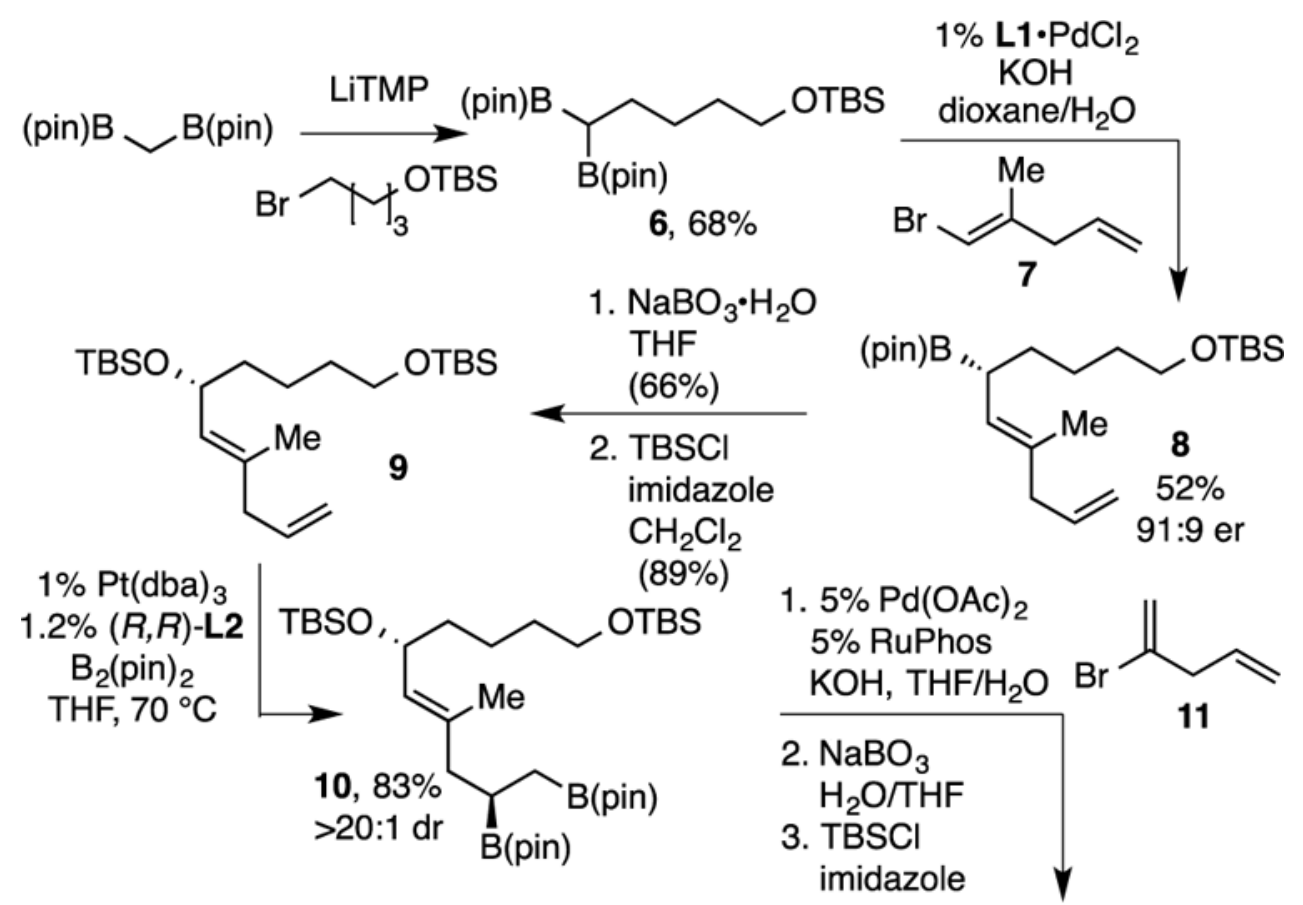

TBSO,

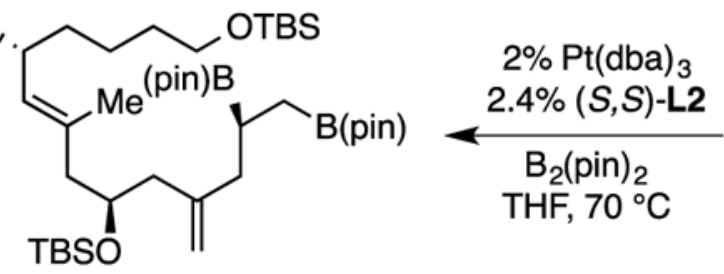

TBSO<smiles>C=CCC(=C)C[C@@H](C/C(C)=C/[CH]CCCCO[Sb])O[Mg]</smiles>

$13,86 \%,>20: 1 \mathrm{dr}$

$12,63 \%$

(3 steps)

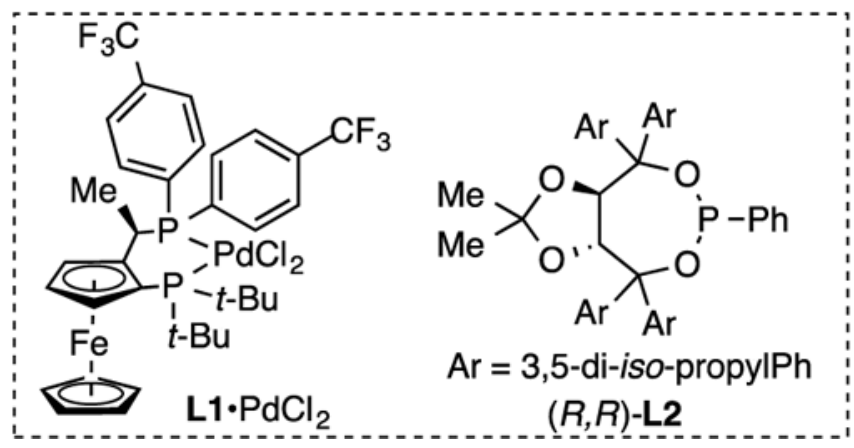

Scheme 2.

Synthesis of Cross-Coupling Partner 13. 

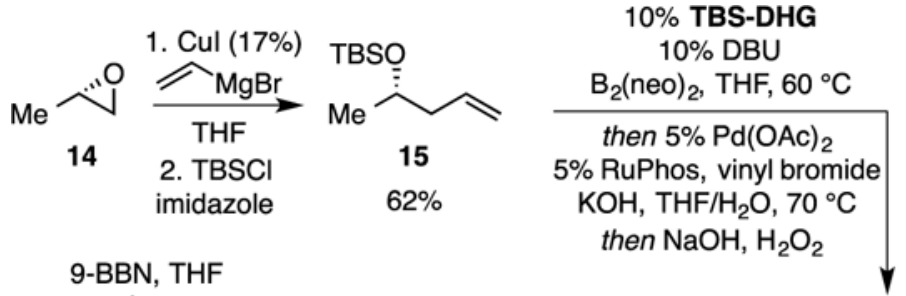

9-BBN, THF

then
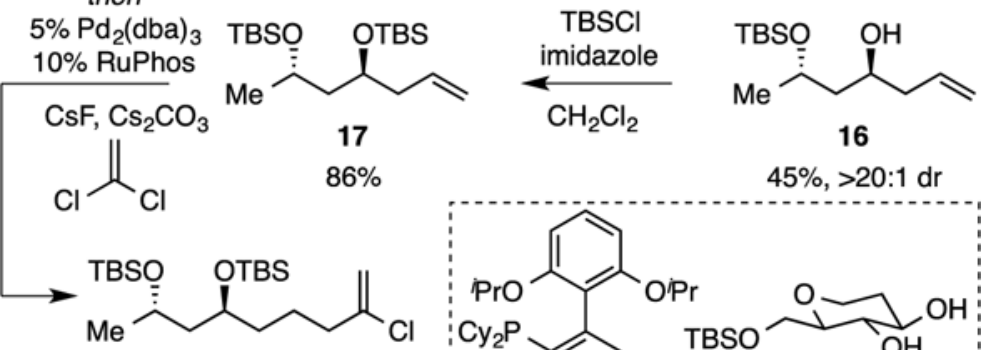

18

$>96 \%$

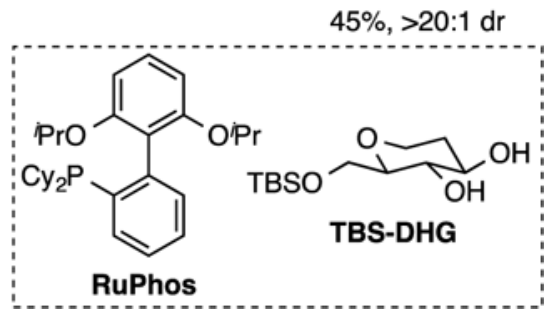

Scheme 3.

Preparation of Cross-Coupling Alkenyl Chloride 18. 
TBSO,

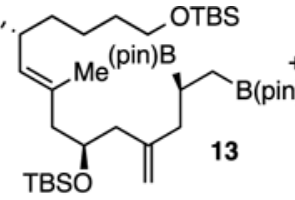

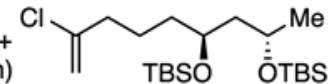

$5 \% \operatorname{Pd}(\mathrm{OAc})_{2}$

$5 \%$ RuPhos

1.<smiles>Oc1cccc2c1OCO2</smiles>

$\mathrm{NaHCO}_{3}$

2. $\mathrm{NaClO}_{2}, \mathrm{NaH}_{2} \mathrm{PO}_{4}$

$t-\mathrm{BuOH}, \mathrm{CH}_{3} \mathrm{CN}$

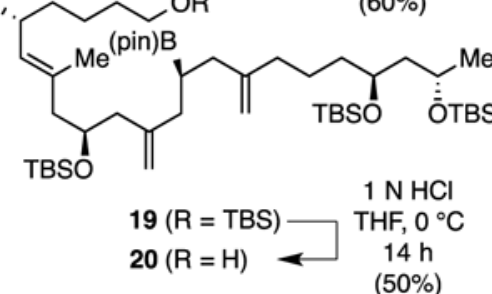

TBSO
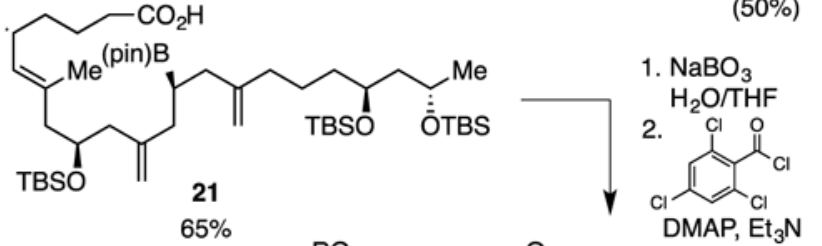

Ro

$(64 \%)$

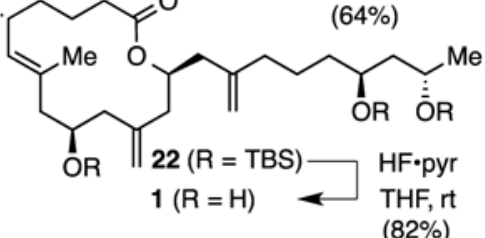

Scheme 4.

Completion of Structure 1 by Suzuki-Miyaura Fragment Coupling. 

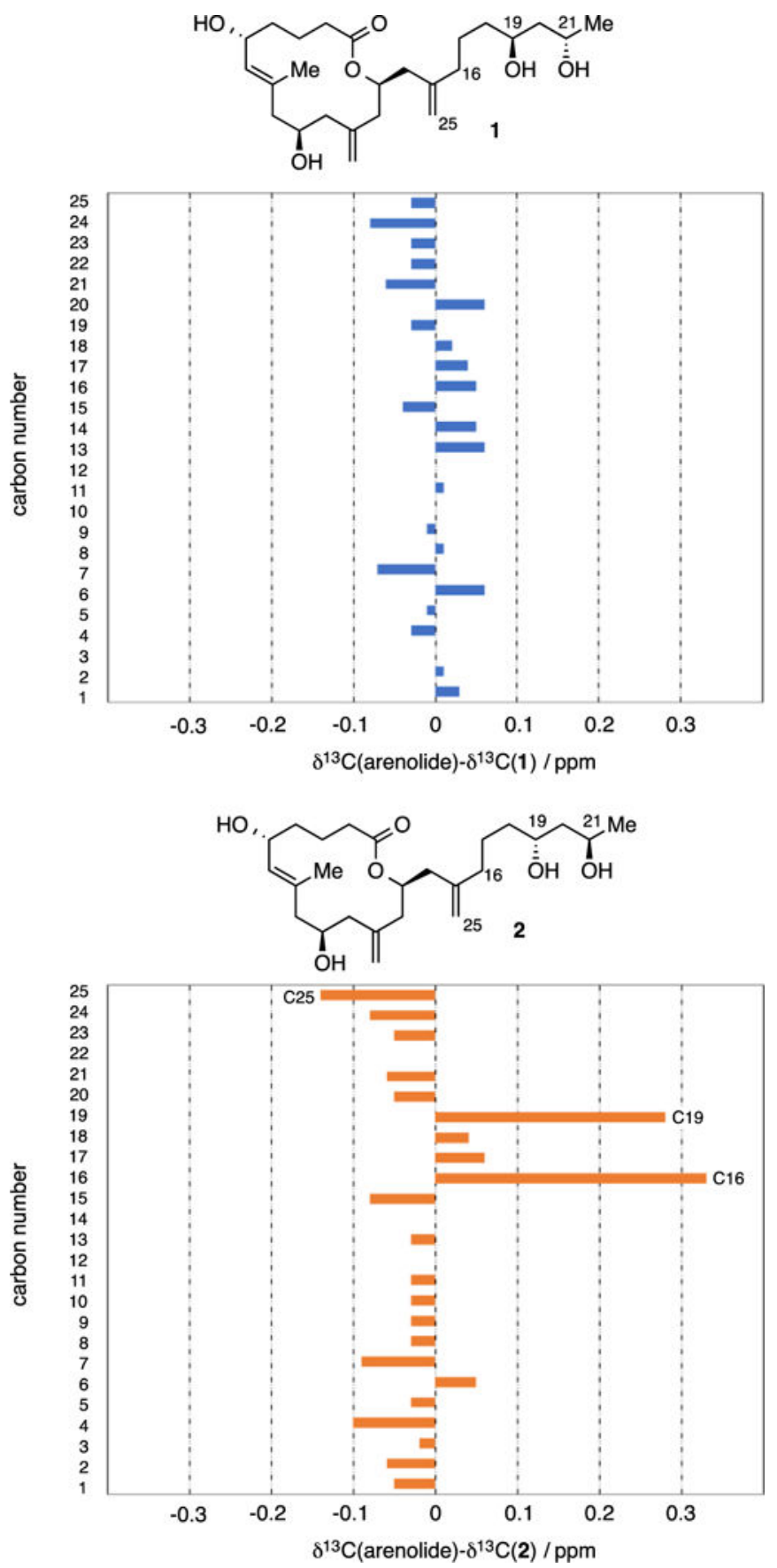

Scheme 5.

Comparison of ${ }^{13} \mathrm{C}$ NMR for Structures 1 and 2 with Naturally Occurring Arenolide Suggests 1 is the Natural Product. 